\title{
An in vitro Model of Chlamydia trachomatis Infection in the Regenerative Phase of the Human Endometrial Cycle
}

\author{
By STEVEN CAMPBELL, ${ }^{1}$ SHIRLEY J. RICHMOND, ${ }^{1}$ * \\ PETER HAYNES,${ }^{2} \dagger$ DIETER GUMP, ${ }^{1} \ddagger$ PETER YATES ${ }^{1}$ \\ AND TERRY D. ALLEN ${ }^{3}$ \\ ${ }^{1}$ Department of Medical Microbiology, Medical School, University of Manchester, \\ Oxford Road, Manchester M13 9PT, UK \\ ${ }^{2}$ Department of Obstetrics and Gynaecology, University Hospital of South Manchester, \\ Nell Lane, Manchester M20 8LR, UK \\ ${ }^{3}$ Department of Ultrastructure, Patterson Laboratories, Christie Hospital and \\ Holt Radium Institute, Wilmslow Road, Manchester M20 9BX, UK
}

(Received 8 February 1988)

\begin{abstract}
An in vitro model of the regenerative phase of the human endometrial cycle was developed in order to study the growth of Chlamydia trachomatis during the period following menses. Glandular epithelial fragments were prepared from curettings of endometria and explanted onto coated substrata. Epithelial cells migrated rapidly from the explant in a fashion which closely mimicked the regeneration of the surface epithelium after menses. The cultures were then experimentally infected with $C$. trachomatis serotype $\mathrm{E}$ at various times during formation of the outgrowth. Chlamydial inclusions developed both within the explants and in the outgrowing epithelial sheets. They were also found in isolated epithelial and non-epithelial cells. However, the most striking feature of chlamydial inclusion development within these cultures was the tendency for inclusions to be located in cells at the periphery of the epithelial sheets. This was partly due to the failure of the cells within the sheets to bind chlamydiae after centrifugation of the organisms onto the culture and partly due to a phenomenon similar to phagokinesis. During this process infectious chlamydial particles were cleared from the substratum by migrating cells with free motile edges, which occasionally led to internalization and inclusion development within these cells.
\end{abstract}

\section{INTRODUCTION}

Ascending chlamydial infection within the female genital tract is now recognized as an important cause of pelvic inflammatory disease, which may result in infertility. The organisms spread from the cervix to involve both endometrium and fallopian tubes, where they establish persistent intracytoplasmic infection within the epithelial cells of these mucosal surfaces. Although chlamydial endometritis and salpingitis are often clinically mild or inapparent, gross disruption to tissue structure and function may occur (Gump et al., 1981; Paavonen et al., 1985). As yet, however, the pattern of chlamydial growth and the cycles of infection and reinfection in these tissues are poorly understood, although there is clinical evidence of more acute infections in the week following menses (Sweet et al., 1986).

$\dagger$ Present address: Milton Keynes General Hospital, Standing Way, Eaglestere, Milton Keynes MK6 5LD, UK.

$\ddagger$ Present address: Department of Medicine, Given Building, University of Vermont, Burlington, Vermont 05405 , USA.

Abbreviations: McIFU, McCoy cell inclusion forming units; FITC, fluorescein isothiocyanate; SEM, scanning electron microscopy. 
An understanding of chlamydial infection of the endometrium and its persistence within that tissue is made more difficult by the existence of highly complex functional and morphological changes that occur during the course of each menstrual cycle (Demopoulos, 1982). Prior to ovulation the epithelial cells of this glandular mucosal surface undergo rapid proliferation. This is followed by a period of secretory differentiation during which proliferation ceases. If a fertilized ovum fails to implant, a period of menses follows in which patches of the endometrium regress, disintegrate and are shed. During the 4 or $5 \mathrm{~d}$ period of menses, local regeneration of the shed surface occurs. This regenerative phase, which lasts 1 or $2 \mathrm{~d}$ in any particular location, is mainly characterized by cell migration from the basal glandular stubs and recolonization of the surface of the denuded stroma to form a new luminal epithelium (Ferenczy, 1975a,b).

Previous examination of chlamydial growth within isolated endometrial cells (Richmond $e t$ $a l ., 1986)$ led us to suggest that chlamydial behaviour during the period of menses and epithelial regeneration may shed light on mechanisms of chlamydial persistence. We have now used a tissue-culture model of the regenerative phase of the human endometrial cycle (Kirk et al., 1978), in order to investigate chlamydial infection at this stage. Fragments of epithelial glands were explanted onto coated substrata so that sheets of epithelial cells grew out in a fashion analogous to regeneration in vivo. Cultures were then infected with a genital isolate of Chlamydia trachomatis and the pattern of inclusion development studied.

\section{METHODS}

Isolation and explantation of endometrial gland fragments. The isolation and culture methods used were a development of those described by Kirk et al. (1978) and Kirk \& Irwin (1980). Curettings were obtained at the time of hysterectomy or as part of dilation and curettage procedures from women in the secretory or proliferative phases of the endometrial cycle, who were undergoing investigation or treatment of non-malignant conditions. This tissue was obtained with the permission of the local ethical committee. The endometrium was chopped into small pieces with a scalpel blade and placed in unsupplemented growth medium (see below) which contained, per $\mathrm{ml}, 1 \mathrm{mg}$ collagenase type I (Sigma), and $1 \mathrm{mg}$ hyaluronidase (Sigma), at $37^{\circ} \mathrm{C}$. After digestion for 20-60 min, the tissue fragments were sedimented by centrifugation at $150 \mathrm{~g}$ for $5 \mathrm{~min}$ and the supernatant, which contained single cells, was discarded. Fresh dissociation mixture was then added and tissue was sheared vigorously by refluxing through a Pasteur pipette. This procedure was repeated up to three times until the large tissue fragments were broken up. The glands were sedimented again by centrifugation then resuspended in phosphate-buffered saline (Dulbecco's PBS without divalent cations, $\mathrm{pH} 7 \cdot 2)$ and filtered through a polyester mesh ( 200 or $400 \mu \mathrm{m}$ pore diameter; Henry Simon, Stockport) in order to remove large tissue fragments which contained undissociated stroma. The filtrate was passed through a finer mesh $(30 \mu \mathrm{m}$ pore size $)$ and the mesh was washed thoroughly with PBS to remove single cells. The filter was then inverted and the trapped glands backwashed into a Petri dish. If many single cells remained in the washing, the last filtration step was repeated, although this resulted in a loss of glandular material. Two types of substratum coatings were used with equal effect to produce attachment and cell outgrowth. An acid extract of rat-tail tendon, largely collagen type I (Elsdale \& Bard, 1972), was used to coat circular glass coverslips, $10 \mathrm{~mm}$ diameter (Chance Propper) or tissue-culture-grade plastic (Nunclon). The acid extract was added to the tissue-culture vessels and incubated at $37^{\circ} \mathrm{C}$ for $1 \mathrm{~h}$. The extract was then removed and the coated surfaces were washed quickly with $0.5 \mathrm{M}$-acetic acid and PBS which contained phenol red. Alternatively, a basement-membrane extract (Matrigel, Collaborative Research) was diluted 50-fold in cold tissue-culture medium and incubated for $1 \mathrm{~h}$ at $37^{\circ} \mathrm{C}$. Coated surfaces were then washed twice with tissue-culture medium.

The growth medium used was a $1: 1$ mixture of HAM's nutrient mixture F-12 and Dulbecco's modified Eagle's medium made from powder which contained 15 mM-HEPES buffer (Sigma). It was supplemented with $10 \%(\mathrm{v} / \mathrm{v})$ foetal calf serum, $14 \mathrm{~mm}$-sodium bicarbonate, $10 \mathrm{ng}$ epidermal growth factor $\mathrm{ml}^{-1}$ (Collaborative Research), $5 \mu \mathrm{g}$ insulin $\mathrm{ml}^{-1}$ (Sigma), $10^{-7} \mathrm{M}$-hydrocortisone (Sigma), $2 \mathrm{mM}$-glutamine, $50 \mu \mathrm{g}$ vancomycin $\mathrm{ml}^{-1}$ and $100 \mu \mathrm{g}$ streptomycin $\mathrm{ml}^{-1}$. Glandular fragments were suspended in this growth medium, and samples were added to plastic flat-bottomed vials (Gibco) which contained a coated glass coverslip. The glands sedimented rapidly and attached to the coverslip. Subsequent changes in the cultures were observed directly on an inverted bright-field microscope (CK, Olympus).

Infection procedure. High-titre stocks of C. trachomatis serotype E strain T181 (Sompolinsky \& Richmond, 1974) were prepared and titrated in McCoy cells (Richmond, 1985). Infectivity was expressed as the number of McCoy cell inclusion-forming units (McIFU). Infection of McCoy cells was always enhanced by centrifugation (2000 $\mathrm{g}$ at $34{ }^{\circ} \mathrm{C}$ for $30 \mathrm{~min}$ ) after inoculation of the organisms. Endometrial cultures were infected in the same way with $2 \times 10^{5}$ McIFU per vial. 
In subsequent experiments the substratum was coated with organisms before explantation of the tissue pieces. One hour before glandular fragments were added to the culture vials, a $1 \mathrm{ml}$ suspension of $10^{6} \mathrm{McIFU}$ in tissueculture medium was centrifuged as above onto collagen-coated coverslips, the supernatant was removed and the coverslips were washed twice with $1 \mathrm{ml}$ tissue culture medium. The vials were then incubated at $37^{\circ} \mathrm{C}$ with $1 \mathrm{ml}$ growth medium, until the gland suspension was added.

Time-lapse photography. The attachment and outgrowth of epithelial cells from the glandular explants was followed by time-lapse photography on an inverted phase microscope. Gland were plated onto collagen-coated tissue culture vessels which were made by bonding the tops of slide flasks (Nunclon) to glass microscope slides with clear silicone rubber (Dow \& Corning). These were less likely to buckle out of the focal plane during recording (Allen, 1987) than conventional plastic flasks. Video time-lapse was carried out with a trinocular inverted phase microscope (Diavert, Leitz) using continuous low-intensity red light. Video images were obtained with an ER Newvicon Camera (National Panasonic), timed with a video timer (FOR-A Company, Tokyo, Japan) and recorded with a $\mathrm{U}$-format machine $(6650 \mathrm{E}, \mathrm{JVC})$ at a fixed lapse rate of approximately $7 \mathrm{~s}$.

Detection of chlamydiae. Cultures were fixed either in industrial-grade ethanol for at least 5 min or in $2 \%(\mathrm{v} / \mathrm{v})$ formaldehyde in PBS for $20 \mathrm{~min}$. Some formaldehyde-fixed cultures were then post-fixed in acetone for at least $15 \mathrm{~min}$ at room temperature to permeabilize the cells. Chlamydial inclusions were visualized by indirect immunofluoresence (IF) with a polyclonal antiserum made by hyperimmunization of a rabbit with yolk-sacpropagated C. trachomatis serotype E (Richmond, 1980) and a fluorescein isothiocyanate (FITC) - anti-rabbit IgG sheep serum conjugate (Sigma). The specificity of staining was further verified by examination of the inclusions with phase-contrast microscopy. Individual chlamydial particles were either visualized in the same way or were stained directly with a commercially available FITC-conjugated monoclonal antibody which contains a rhodamine counterstain (Syva).

Cytoskeletal characterization. Cultures were fixed in industrial-grade ethanol as above, then the epithelial nature of the explants and cells which had attached to the substratum was examined with a polyspecific monoclonal antibody to the cytokeratin family (Sanbio) and visualized with an affinity-purified tetramethyl rhodamine isothiocyanate-conjugated (TRITC) - anti-mouse goat serum (Zymed) diluted 1 in 10 in $10 \%$ normal goat serum in PBS.

Cellular organization in the explant and outgrowth was further characterized by the staining of the actinmicrofilaments (F-actin) with rhodamine-phalloidin (Molecular Probes) after fixation and permeabilization with formaldehyde and acetone (see above). The microtubules were stained in order to visualize the ciliated epithelial cells. Tubulin staining was carried out with a Cytolite kit (DuPont) according to the manufacturer's instructions. This involved an initial crosslinking step with dithio-bis-(succinimidyl propionate), washing with a stabilizing buffer, extraction with Triton X-100 and post-fixation in methanol. Although this method resulted in very clear visualization of the microtubules, the extraction step disrupted the chlamydial inclusion membrane.

Microscopy. Fluorescent specimens were examined on a Dialux microscope (Leitz) fitted with an epi-illuminator and phase optics. Photographs were taken on Technical Pan film (Kodak) which was developed in D76 1+1 for 11 min or with HP5 (Ilford) developed in Microphen (Ilford) for the same time. Cultures for scanning electron microscopy (SEM) were fixed in $2 \%(\mathrm{w} / \mathrm{v})$ vacuum-distilled glutaraldehyde dissolved in unsupplemented growth medium and stored at $4{ }^{\circ} \mathrm{C}$ for several days. After $1 \mathrm{~h}$ post-fixation in $1 \%(\mathrm{w} / \mathrm{v})$ osmium textroxide, the specimens were dehydrated in a graded series of ethanol/water solutions, transferred to trichlorotrifluoroethane (Arklone ICI), critical-point dried from carbon dioxide and sputter-coated with $5 \mathrm{~nm}$ of gold. The specimens were observed in an ISI SS40 scanning microscope operated at an accelerating potential of $20 \mathrm{kV}$.

\section{RESULTS}

\section{Characterization of the culture model}

The behaviour of the explants was followed by time-lapse photography over a $3 \mathrm{~d}$ period to determine whether events in culture resembled the outgrowth of cells during the regenerative phase in vivo. The start of outgrowth from gland fragments varied from $4 \mathrm{~h}$ to $2 \mathrm{~d}$ after planting. In the example illustrated (Fig. 1), attachment and outgrowth started after $4 \mathrm{~h}$. Complete dissociation of some, but not all, of the smaller explants occurred and in the illustrated cultures dissociation was complete in $24 \mathrm{~h}$. A small number of single cells were usually present in the initial suspension and they too attached, spread and began to migrate over the substratum in the same period. The identity of these single cells could not be established on morphological grounds alone. Direct observation, real-time and time-lapse photography with a $40 \times$ objective revealed that a minority of the cells in the explants and outgrowth possessed asynchronously beating cilia. During the first $36 \mathrm{~h}$ of culture no cell division occurred in the outgrowing epithelial sheets. After that period occasional divisions were observed at the edge of the cell sheets. 

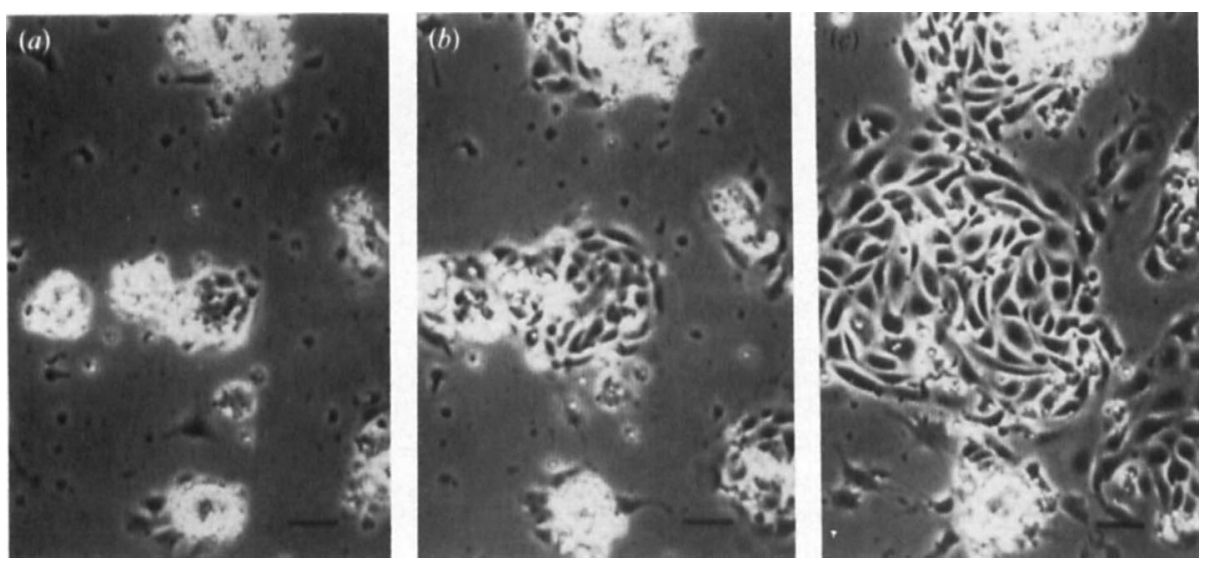

Fig. 1. Still frames from a video time-lapse sequence which shows six explants of different sizes $(a) 5 \mathrm{~h}$, (b) $9 \mathrm{~h}$, and $(c) 19 \mathrm{~h}$ after plating. These demonstrate the rapid break-up of the smaller explants, the gradual fusion of outgrowths from neighbouring explants, and the presence of single cells at the time of plating. Bars, $100 \mu \mathrm{m}$.

SEM was used to see whether the normal surface topography of individual cells was maintained in vitro, and to determine the orientation of cells within the explant. Examination of the explants revealed that the luminal surface of the gland, i.e. the apical surface of the cell, was always located on the outside of the explants. The surface topography of these cells was similar if not identical to their in vivo counterparts after $1 \mathrm{~d}$ in culture (Kirk et al., 1978). The majority of the cells were microvillous (Fig. $2 a$ ) but occasional cells were ciliated.

Within the outgrowth the epithelial cells became thinner and more well spread, like their in vivo counterparts during the course of surface recolonization (Ferenczy \& Richart, 1974; Ferenczy 1975a, $b$; Hafez et al., 1975). The apical surface of these cells was characteristically microvillous (Trent et al., 1980) although the microvilli were shorter and less densely packed together, like those found during regeneration in vivo. A small and highly variable number of cells were ciliated (Masterton et al., 1975). The peripheral cells at the edges of the sheet had smooth, thin lamellipodia (Fig. $2 b$ ) characteristic of motile epithelial cells at the edges of cell sheets (Dipasquale, 1975a,b).

The components of the cytoskeleton were examined in order to establish epithelial cell identity by light microscopy, and to further characterize the migration of the epithelial sheets. Factin was stained with rhodamine-phalloidin, which demonstrated that most of the polymerized actin was present at the cell periphery. This distribution permitted visualization of the cellular organization in the explants. The cells on the surface of large explants were organized in an epithelial cobblestone pattern (Fig. $3 a$ ). During the course of migration, the cells of the outgrowth started to spread out so that the densely packed cobblestone appearance was lost. The spread cells had the usual subapical actin bundles and stress fibres which ran on a more basal plane close to the substratum. The stress fibres in neighbouring cells were often in juxtaposition to one another so that they appeared to form a circumferential band (Fig. $3 b$ ). Tubulin staining of the culture confirmed the time-lapse and SEM observations on the low frequency of ciliated cells. Keratin staining is dealt with below.

\section{Effect of centrifugation on growth of chlamydiae}

Preliminary experiments demonstrated that centrifugation was required in order to achieve inclusion development in this culture system. When outgrowths of glandular explants were either incubated with $25 \mu \mathrm{l}$ inocula of $2 \times 10^{5} \mathrm{McIFU}$ for $2 \mathrm{~h}$ in a humidified chamber, or continuously incubated for $2 \mathrm{~d}$ with the same inoculum in $1 \mathrm{ml}$ of medium, no inclusions developed. This result is at variance with that obtained by Moorman et al. (1986), where centrifugation did not affect the number of inclusions that developed. However, their culture system involved the use of a different substratum (fibronectin) and a higher inoculum of 

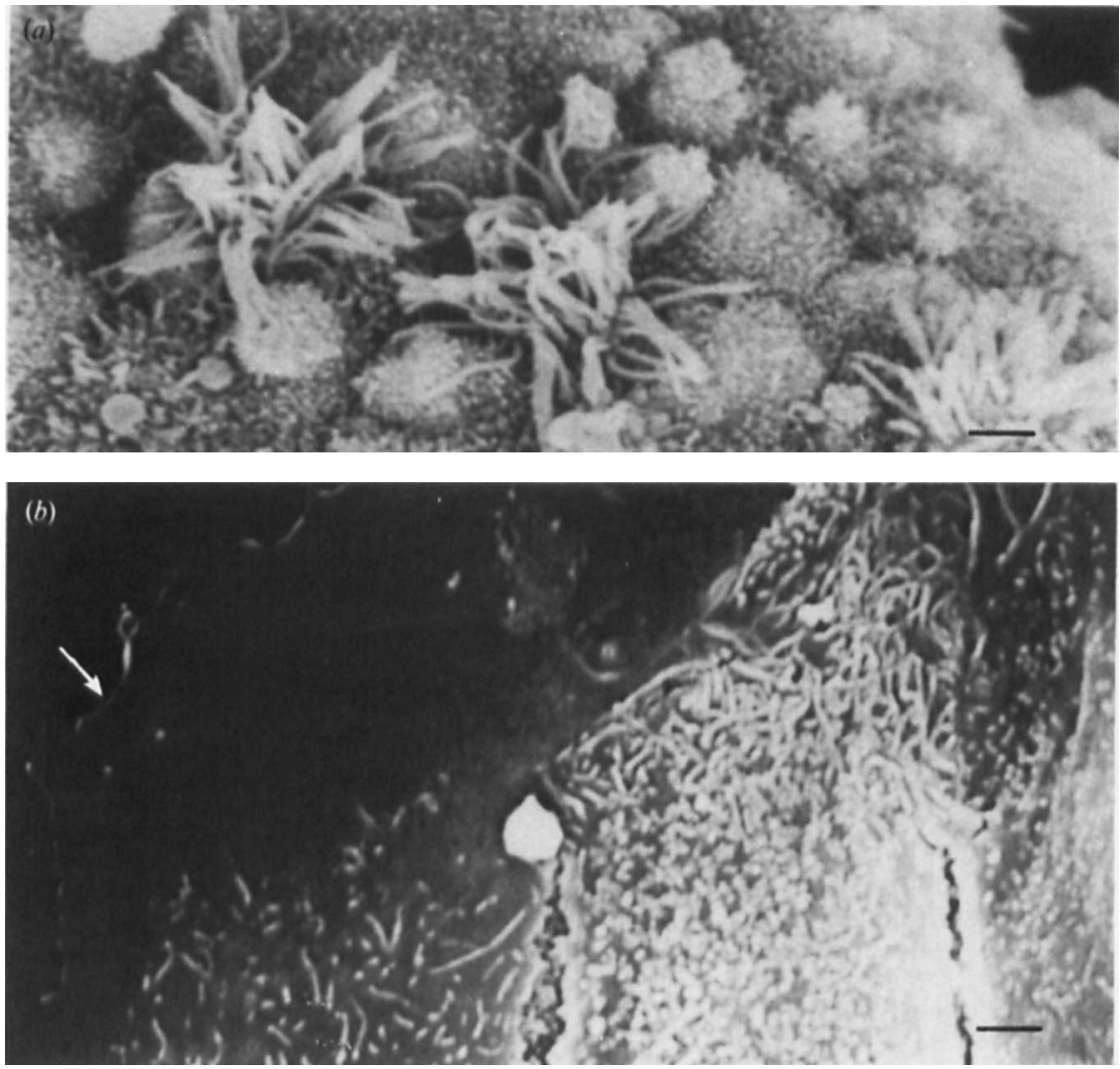

Fig. 2. (a) Scanning electron micrograph of the surface of an explant $21 \mathrm{~h}$ after plating. The apical surfaces of the cells are densely covered by microvilli; a minority are ciliated. $(b)$ Scanning electron micrograph of a peripheral microvillous cell of an outgrowth which shows a thin smooth-surfaced lamellipodium (arrow). Bars, $2 \mu \mathrm{m}$.
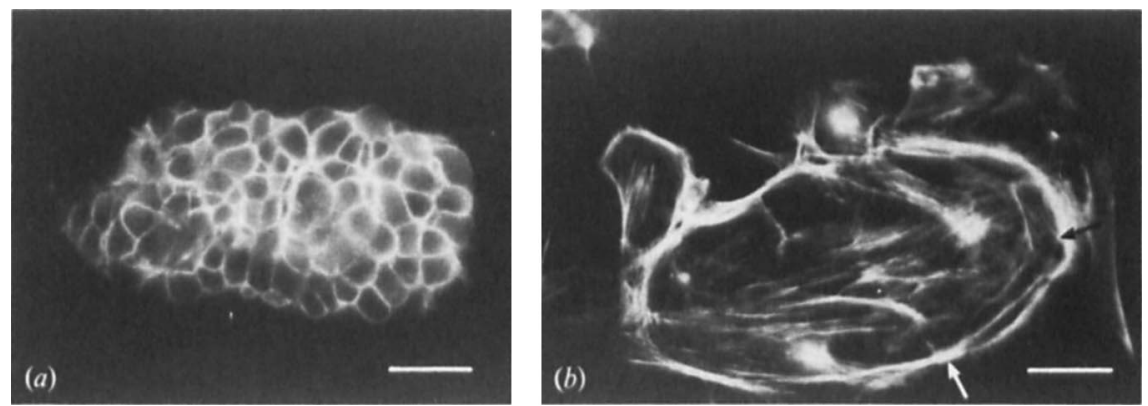

Fig. 3. Rhodamine-phalloidin staining of the filamentous actin. (a) An explant after $21 \mathrm{~h}$ of culture. The peripheral distribution of actin within individual epithelial cells gives rise to the characteristic staining pattern of the surface of the explant. (b) An epithelial island of approximately 15 cells. These well-spread cells contain prominent stress fibres, particularly at their periphery (arrows), where they form a prominent circumferential band around the sheets as a whole. Bars, $30 \mu \mathrm{m}$.

organisms. In our glandular outgrowth model, even after centrifugation the number of inclusions found was about 50-fold less than the number of inclusions in control McCoy cell monolayers inoculated with the same number of McIFU. However, meaningful quantification of inclusion development was impossible because of the complexities and variation of outgrowth formation and the very uneven distribution of inclusions. 

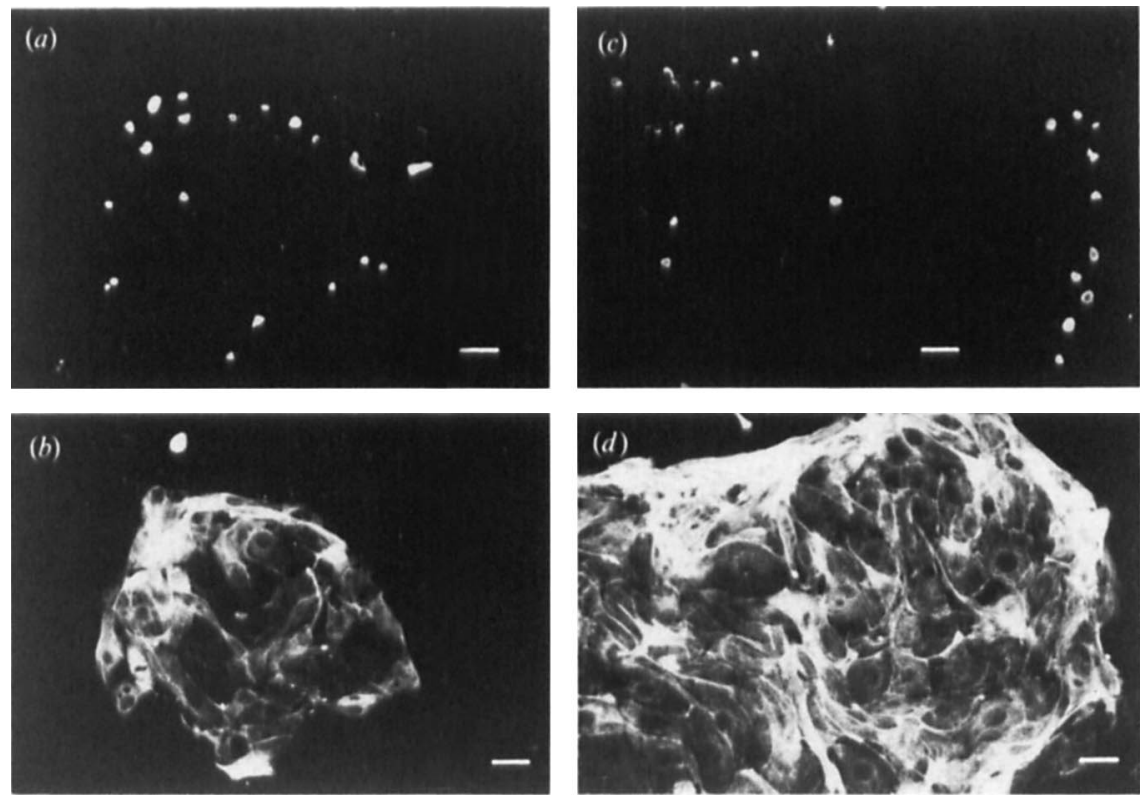

Fig. 4. The distribution of chlamydial inclusions in epithelial outgrowths. Cultures were infected $1 \mathrm{~d}$ after plating and fixed $2 \mathrm{~d}$ later. $(a, c)$ Inclusions. These were stained with a polyclonal rabbit serum to chlamydia and a FITC-conjugated anti-rabbit sheep serum. $(b, d)$ The same cell sheets stained with a mouse monoclonal antibody to cytokeratin and a TRITC-conjugated anti-mouse goat serum. All cells within the outgrowths are epithelial. Inclusions were distributed at the periphery of isolated outgrowths $(a, b)$ and at the periphery and in the junctional zone between two outgrowths from different explants $(c, d)$. Bars, $30 \mu \mathrm{m}$.

\section{Inclusion distribution in endometrial cultures}

The overall distribution of inclusions within the epithelial outgrowths was examined by immunolocalization of both chlamydial inclusions and cytokeratin filaments present within the epithelial cell cytoplasm (Moll et al., 1983). The dual staining patterns demonstrated that inclusions tended to form in the most peripheral keratin-staining cells of the outgrowths or in their close neighbours (Fig. $4 a, c$ ). When epithelial sheets from adjacent explants became contiguous after infection, inclusions were also found in the junctional regions (Fig. $4 c, d$ ), and if cultures were infected 48 rather than $24 \mathrm{~h}$ after plating, the same peripheral distribution of inclusions was maintained. However, if cultures were infected after $4 \mathrm{~d}$, by which time large confluent areas of epithelial cells were present, few inclusions developed in the confluent areas.

The peripheral distribution of inclusions in glandular outgrowths could be seen when live cultures were examined with an inverted phase microscope $1 \mathrm{~d}$ post-infection. Retrospective analysis of time-lapse sequences demonstrated that both infected and uninfected cells which were in a peripheral location shortly after centrifugation maintained that position during the course of outgrowth and inclusion development. This behavioural pattern has been observed in other uninfected epithelial culture systems (Dipasquale, 1975b). Infected cells therefore appeared to retain their normal locomotory behaviour during the early stages of inclusion development.

Keratin staining of the cultures revealed that both the isolated stromal cells (Fig. 5) and the epithelial cells present at the time of plating could support the development of chlamydial inclusions. Occasional small round inclusions were also seen within the explants themselves and at sites where small explants had entirely dissociated to form very closely packed monolayers at the centre of epithelial islands. Although almost all explants stained for keratin, occasional nonstaining explants were seen, which also sometimes contained small round inclusions. Inclusion formation was therefore not restricted solely to epithelial cells. 

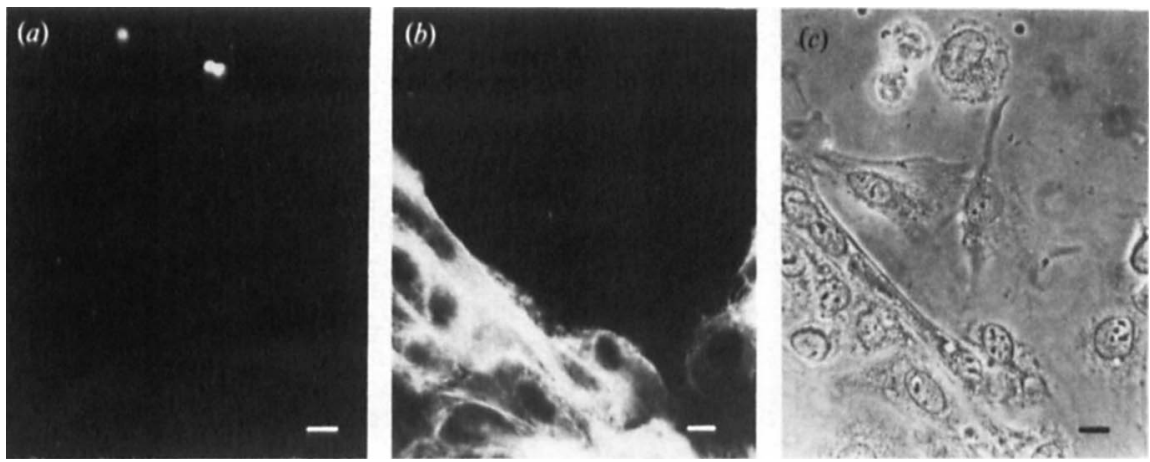

Fig. 5. Chlamydial inclusions in stromal cells. Inclusions $(a)$ at the edge of a keratin-positive epithelial sheet $(b)$ where two keratin-negative cells are demonstrated by phase optics $(c)$. Staining techniques were as described in Fig. 4. Bars, $10 \mu \mathrm{m}$.
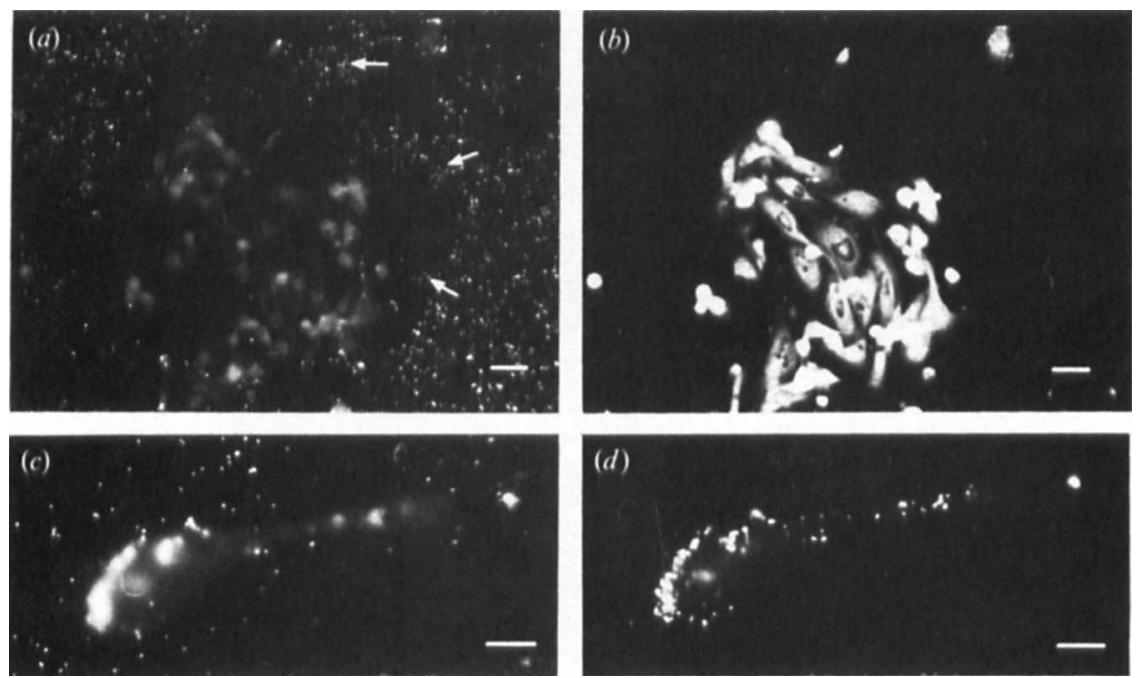

Fig. 6. Uptake of chlamydiae from the substratum. A collagen-coated coverslip was precoated with a crude inoculum of chlamydiae and explants were plated $1 \mathrm{~h}$ later. Cultures were fixed $50 \mathrm{~h}$ later. (a) Chlamydiae stained with a FITC-conjugated monoclonal antibody (some are indicated by arrows); $(b)$ the same field showing cells counterstained with rhodamine. Chlamydiae were removed from the substratum in the vicinity of a group of cells, but remained evenly distributed over cell-free areas. An individual cell $(c)$ removed chlamydiae from the plane of the substratum onto a higher plane on the cell surface and within the cytoplasm $(d)$. Bars $(a, b), 30 \mu \mathrm{m},(c, d), 3 \mu \mathrm{m}$.

\section{Factors which may contribute to the peripheral distribution of inclusions in outgrowths}

To gain insight into why the majority of inclusions developed at the periphery of glandular explants, cultures were fixed immediately after centrifugation and the binding of chlamydial particles was compared qualitatively with the binding of chlamydia to confluent control McCoy cell monolayers. There was a striking dissimilarity between the two types of culture. As previously observed by Moorman et al. (1986), chlamydial particles were evenly distributed over the McCoy cell monolayers, whereas in the endometrial cultures very few particles were located either on areas of confluent epithelial sheets or on the explants themselves, despite a uniform distribution of particles on the collagen-coated glass in cell-free areas. This raised the possibility that centrifugation presented chlamydiae to the cell by depositing them on the surrounding substratum, from which they were subsequently 'scavenged' during the course of radial migration. 

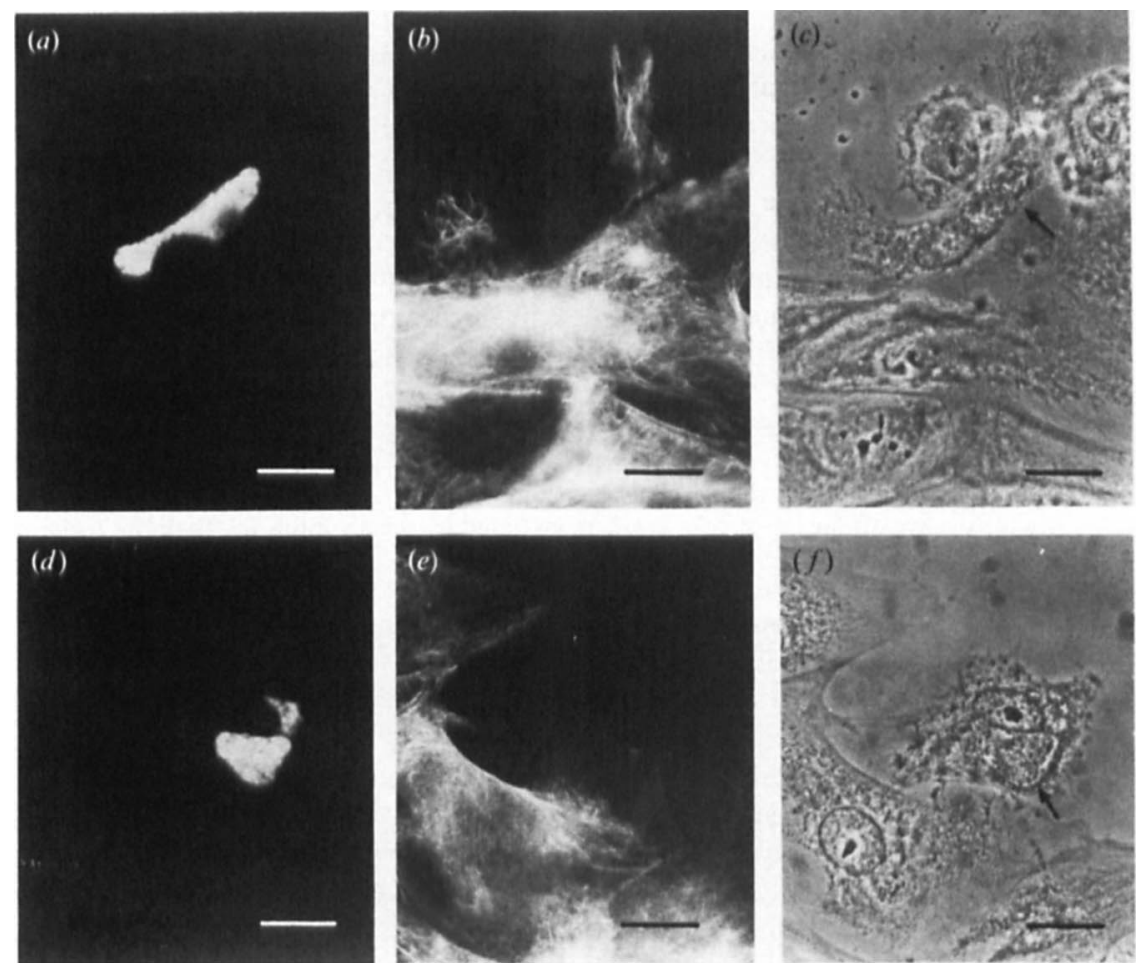

Fig. 7. Pleomorphic chlamydial inclusions in epithelial and stromal cells. Cultures were fixed $50 \mathrm{~h}$ after the substratum had been precoated with chlamydia as in Fig. 6 . Inclusions and cytokeratin filaments were stained as in Fig. 4. (a) A pleomorphic inclusion in (b) a keratin-positive cell at the periphery of a cell sheet. $(c)$ Phase image of infected cell showing position of inclusion (arrow). This shows that the indentation of the inclusion was caused by close approximation of the nucleus. (d) A similar inclusion in a keratin-negative cell near $(e)$ the periphery of an epithelial (keratin-positive) cell sheet. $(f)$ The keratin-negative cell by phase optics showing position of inclusion (arrow). Bars, $5 \mu \mathrm{m}$.

In order to test this possibility, $10^{6} \mathrm{McIFU}$ were centrifuged onto the coverslips (see Methods), and explants were then plated onto them within $1 \mathrm{~h}$. Examination of fixed cultures 2 or $3 \mathrm{~d}$ later revealed that areas of the substratum around epithelial sheets were cleared of chlamydial particles (Fig. $6 a, b$ ). Both keratin-staining and non-staining cells were seen to have removed chlamydiae from the plane of the substratum to a higher plane either within the cell or on its surface (Fig. 6c,d). These observations were confirmed by SEM, which showed that both cells at the periphery of outgrowths and isolated, smooth-surfaced stromal cells (Trent et al., 1980; Kirk et al., 1978) had many small particles on their upper surfaces, whereas cells within epithelial sheets had clean microvillous or ciliated surfaces as seen in uninfected cultures (Fig. 2).

This 'pick-up' of chlamydiae from the substratum resulted in inclusion development in epithelial cells at the periphery of the cell sheet (Fig. $7 a-c$ ) and within isolated epithelial and stromal cells (Fig. $7 d-f$ ). No inclusions were seen within explants or at the centre of the cell sheets. However, a far smaller number of inclusions resulted from this mode of infection than from conventional infection of established cultures, despite the five-fold higher inoculum of organisms. This may have been due to a loss of chlamydial viability when organisms were attached to the collagen, during the period of explant attachment and outgrowth. 


\section{DISCUSSION}

The culture system described here modelled many important features of cell behaviour which characterize the regenerative phase of menses. The outgrowth patterns obtained were similar to those described by Kirk et al. (1978), except that migration of ciliated cells was not detected in their system. Such outgrowth does, however, represent a feature of the regenerative process in vivo (Hafez \& Ludwig, 1977). The stage of the menstrual cycle at which curettings were obtained was not crucial for our model, since successful outgrowths were obtained from both proliferative and secretory phase specimens in the absence of either oestrogen or progesterone supplementation of the culture medium. Indeed, by excluding these hormones we attempted to simulate the hormonal milieu of menses, when serum oestradiol-17 $\beta$ and progesterone are at their lowest levels (Lenton et al., 1982).

Most previous studies of chlamydial growth in cultured cells have used monolayers formed from isolated cells. In contrast, in this work we attempted to study chlamydial infection in nonproliferating migratory sheets of epithelial cells since such cell sheets mimic the in vivo situation during menses more closely. Although changes of phenotype may have occurred within individual cells (e.g. exaggerated cell spreading, changes in surface topography and reorganization of the cytoskeleton), the cells remained as coherent, non-proliferating migratory sheets with well-defined edges during the period of culture.

An important limitation of our model is that it only dealt directly with the de novo infection of cells during the course of regeneration. However, it is likely that within the infected uterus some of the glandular stubs will contain cells with inclusions at the time of menses. Our observations on the motility of infected cells suggest that they may migrate onto the lumenal surface of the denuded stroma during regeneration of the epithelium. Attempts to test this possibility directly, either by centrifugation of chlamydiae onto newly isolated glandular fragments or by incubation of organisms with these tissue pieces failed, firstly because centrifugation caused mechanical breakup and loss of viability of the glands, and secondly because no inclusions developed without centrifugation.

Although the distribution of inclusions was influenced by the presence of cell sheets, there were striking similarities between the morphology of inclusions found in isolated cells and those found at the edges of cell sheets. In particular, pronounced pleomorphism of inclusions (Richmond 1985; Richmond et al., 1986) was observed in motile cells of both epithelial and stromal origin. The control of inclusion shape and the interaction with cytoskeletal components is currently under investigation and will be discussed elsewhere.

The occasional development of inclusions within the explant after centrifugation clearly demonstrated that some cells were infected by direct binding of chlamydiae to the cell surface in the classical fashion. However, the tendency for inclusions to form in the most peripheral areas of the cell sheets indicates that the cells in that position had some property not shared by cells without free edges. It is known, for example, that cells at the periphery of cell sheets have a high turnover of surface receptor molecules (Hopkins, 1985). This may have resulted in greater chlamydial binding to the peripheral cells of the outgrowth. Differential association of chlamydiae with a subpopulation of endometrial cells was observed by Moorman et al. (1986). However, in our experiments it was impossible to study variation in chlamydial particle density over the sheets as a whole, because the inoculum of organisms, which was adjusted to produce one inclusion per cell in a confluent McCoy cell monolayer, resulted in very sparse binding in the endometrial system.

In contrast, many chlamydial particles were seen bound to the collagen-coated substratum. Uptake, internalization and intracytoplasmic development of such particles by motile single cells or peripheral cells of migratory epithelial sheets provides an alternative explanation for the inclusion distribution we observed. Association of bacteria with extracellular matrix components has already been described for staphylococci (Maxe et al., 1986) streptococci (Switalski et al., 1982) and Escherichia coli (Froman et al., 1984; Speziale et al., 1982). The subsequent host cell removal of chlamydiae from the substratum that we observed was probably analogous to the non-specific removal of particles by motile epithelial cells (Dipasquale, 1975 a, b). The combined process of removal and internalization resembled phagokinesis, described in 
3 T3 fibroblasts (Albrecht-Buehler \& Goldman, 1976; Albrecht-Buehler, 1977) and endothelial cells (McAuslan \& Reilly, 1980). These cells removed small loosely attached gold particles $(0 \cdot 2-$ $0.4 \mu \mathrm{m}$ diameter) from protein-coated glass during the course of migration and spreading. The attached particles were pulled physically from the substratum, deposited on the upper surface of the cells, and a proportion of them were then internalized (Albrecht-Buehler \& Lancaster, 1976; Albrecht-Buehler \& Bushnell, 1979). Similar activity was observed in McCoy cells, which removed and internalized chlamydiae attached to glass (S. C., unpublished observations).

We envisage that removal of chlamydiae from the substratum is a non-specific activity which can be carried out by a variety of motile epithelial and non-epithelial cells. The exact mechanism of removal is likely to be dependent on the precise culture conditions, the cell type and the nature of the substratum (Albrecht-Buehler \& Lancaster, 1976; McAuslan \& Reilly, 1980; Campbell et al., 1984). Lamellipodial extension and retraction cycles (Dispasquale, 1975a,b), which occur at the advancing edges of endometrial epithelial cells, are probably involved. When part of a leading lamella attaches to a loosely bound chlamydial organism, the tractive forces applied by the cell will result in removal of the bacterium, rather than the extension of the cell into that domain. On occasions this will lead to internalization and productive infection by one of the proposed mechanisms (Soderlund \& Kihlstrom, 1983; Ward \& Murray, 1984; Hodinka \& Wyrick, 1986; Pearce, 1986) in isolated cells or in those at the periphery of migratory cell sheets. Since the exact mechanism of internalization is not yet known, we suggest that the term 'kinetoendocytosis' is used to describe the scavenging and internalization processes which sometimes lead to productive chlamydial infection.

It is not yet clear whether kinetoendocytosis is sufficient to account for all the inclusions that developed in peripherally located cells when chlamydiae were inoculated after glandular explants had attached to the substratum. Such infection will be influenced by the rate at which cells migrate across the substratum and by the length of time that organisms attached to the collagen remain viable. Since kinetoendocytosis is not restricted to epithelial cells, the phenomenon does not explain why $C$. trachomatis infection is restricted to glandular epithelial cells in vivo. Here additional factors, such as the presence of a biochemically complex threedimensional extracellular matrix (Faber et al., 1986) and the behaviour of stromal cells within such matrices, may be important. Nevertheless, kinetoendocytosis may play a significant part in maintaining chlamydial infection of the endometrium, both during menses, and when there is intermenstrual epithelial loss due to chlamydial endometritis. It may also be an important mechanism which ensures reinfection of cells after trauma to other chlamydia-infected epithelia. Autolysis of infected cells shed at such times may result in increased release of infectious organisms. Kinetoendocytosis of organisms bound to the extracellular matrix during regeneration of the epithelium would then ensure persistence of the infection.

\section{REFERENCES}

AlbReCHT-Buehler, G. (1977). The phagokinetic tracts of 3T3 cells. Cell 11, 395-404.

Albrecht-Buehler, G. \& Goldman, R. D. (1976). Microspike-mediated particle transport towards the cell body during early spreading of 3T3 cells. Experimental Cell Research 97, 329-339.

Albrecht-BueHLER, G. \& LANCASTER, R. (1976). A quantitative description of the extension and retraction of surface protrusions in spreading $3 \mathrm{~T} 3$ mouse fibroblasts. Journal of Cell Biology 71, 370-382.

Albrecht-Buehler, G. \& Bushnell, A. (1979). The orientation of centrioles in migrating 3T3 cells. Experimental Cell Research 120, 111-118.

Allen, T. D. (1987). Time lapse video microscopy using an animation control unit. Journal of Microscopy 147, 129-135.

Campbell, S., Allen, T. D. \& Aplin, J. D. (1984). Novel substratum-dependent dentritic morphology and motility in epithelial cells. European Journal of Cell Biology 34, 275-280.

Demopoulos, R. J. (1982). Normal endometrium. In Pathology of the Female Genital Tract, 2nd edn, pp. 235-278. Edited by A. Blaustein. Berlin: Springer.

Dipasquale, A. (1975a). Locomotion of epithelial cells. Experimental Cell Research 95, 425-439.

DIPASQUALE, A. (1975b). Locomotory activity of epithelial cells in culture. Experimental Cell Research, 94, 191-215.

ElsDale, T. \& BARD, J. (1972). Collagen substrate for studies on cell behaviour. Journal of Cell Biology 54, 626-637.

Faber, M., WeVer, U. M., Berthelsen, J. G., Liotta, L. A. \& AlRECHTEN, R. (1986). Laminin production by human endometrial stomal cells relates to the cyclic and pathologic state of the endometrium. American Journal of Pathology 124, 384-391. 
FERENCZy, A. (1975a). Studies on the cytodynamics of human endometrial regeneration. I. Scanning electron microscopy. American Journal of Obstetrics and Gynecology 124, 64-74.

FERENCZY, A. $(1975 b)$. Studies on the cytodynamics of human endometrial regeneration. II. Transmission electron microscopy and histochemistry. American Journal of Obstetrics and Gynecology 124, 582-595.

FERENCZY, A. \& RICHART, R. M. (1974). Scanning and transmission electron microscopy of the human endometrial surface epithelium. Journal of Clinical Endocrinology and Metabolism 36, 999-1008.

Froman, G., Switalski, L. M., Faris, A., Wadstrom, T. \& HooK, M. (1984). Binding of Escherichia coli to fibronectin. Journal of Biological Chemistry 23, 14899-14905.

Gump, D. W., Dickstein, S. \& Gibson, M. (1981) Endometritis related to Chlamydia trachomatis infection. Annals of Internal Medicine 95, 61-63.

Hafez, E. S. E. \& LudwiG, H. (1977). Scanning electron microscopy of the endometrium. In Biology of the Uterus, 2nd edn, pp. 309-340. Edited by R. M. Wynn. New York: Plenum Press.

Hafez, E. S. E., Barnhart, M. J., Ludwig, H., Lusher, J., Joelsson, J., Daniel, J. L., Sherman, A. I., Jordan, J. A., Wolf, H., Stewart, W. C. \& Chretien, F. C. (1975). Scanning microscopy of human reproductive physiology. Acta obsterica et gynecologica scandinavica Supplement 40, 5-61.

HodinKA, R. L. \& WYRICK, P. B. (1986). Ultrastructural study of mode of entry of Chlamydia psittaci into L-929 cells. Infection and Immunity 54, 855-863.

Hopkins, C. R. (1985). The appearance and internalisation of transferrin receptors at the margins of spreading human tumour cells. Cell 40, 199-208.

Kirk, D., King, R. J. B., Heyes, J., Peachy, L., HirSCH, P. J. \& TAYLOR, R. W. (1978). Normal human endometrium in cell culture. I. Separation and characterisation of epithelial and stromal components in vitro. In Vitro 14, 651-662.

KIRK, D. \& IRWIN, J. C. (1980). Normal human endometrium in cell culture. Methods in Cell Biology 21B, 51-77.

Lenton, E. A., Sulaiman, R., Sobowale, O. \& Cooke, I. D. (1982). The human menstrual cycle: plasma concentrations of prolactin, LH, FSH estradiol and progesterone in conceiving and non-conceiving women. Journal of Reproduction and Fertility 65, 131139.

Masterton, R., Armstrong, E. M. \& More, I. A. R. (1975). The cyclical variation in the percentage of cilliated cells in the normal human endometrium. Journal of Reproduction and Fertility 42, 537-540.

MaXe, I., Ryden, C., Wadstrom, T. \& Rubin, K. (1986). Specific attachment of Staphylococcus aureus to immobilised fibronectin. Infection and Immunity 54, 695-704.

MCAuslan, B. R. \& ReIlly, W. (1980). Endothelial cell phagokinesis in response to specific metal ions. Experimental Cell Research 130, 147-157.
Moll, R., LeVy, R., Czernobilsky, B., HohlweGMajert, P., Dallenbach-Hellweg, G. \& Franke, W. W. (1983). Cytokeratins of normal epithelia and some neoplasms of the female genital tract. Laboratory Investigation 49, 599-610.

Moorman, D. R., Sixbey, J. W. \& Wyrick, P. B. (1986). Interaction of Chlamydia trachomatis with human genital epithelium. Journal of General Microbiology 132, 1055-1067.

PaAvonen, J., Aine, R., Teisala, K., Heinonen, P. K., Punnonen, R., Lehtinen, M., Miettinen, A. \& Gronroos, P. (1985). Chlamydial endometritis. Journal of Clinical Pathology 38, 726-732.

Pearce, J. H. (1986). Early events in chlamydial infection. Annales de l'Institut Pasteur/Microbiologie 137A, 307-356.

RichmoND, S. J. (1980). Chlamydial group antigen in McCoy cells infected with Chlamydia trachomatis and Chlamydia psittaci. FEMS Microbiology Letters $8,47-50$.

RICHMOND, S. J. (1985). Division and transmission of inclusions of Chlamydia trachomatis in replicating McCoy cell monolayers. FEMS Microbiology Letters 29, 49-52.

Richmond, S. J., Crosdale, E., Lusher, M. \& HAYNES, P. (1986). Inclusion division and pleomorphism in cultured human endometrial cells. In Chlamydial Infections, pp. 63-66. Edited by D. Oriel, D. Ridgeway, J. Schachter, D. Taylor-Robinson \& M. Ward. London: Cambridge University Press.

SODERLUND, G. \& KiHLSTROM, E. (1983). Attachment and internalisation of a Chlamydia trachomatis lymphogranuloma venereum strain by McCoy cells : kinetics of infectivity and effect of lectins and carbohydrates. Infection and Immunity 42, 930-935.

SOMPOLINSKY, D. \& RichmoND, S. J. (1974). Growth of Chlamydia trachomatis in McCoy cells treated with cytochalasin B. Applied Microbiology 28, 912-914.

Speziale, P., Hook, M. \& Wadstrom, T. (1982). Binding of the basement membrane protein laminin to Escherichia coli. FEBS Letters 146, 55-58.

SWEEt, R. L., Blankfort-Doyle, M., Robbie, M. O. \& SCHACHTER, J. (1986). The occurrence of chlamydial and gonococcal salpingitis during the menstrual cycle. Journal of the American Medical Association 255, 2062-2064.

Switalski, L. M., LuUngh, A., Ryden, C., Rubin, K., HoOK, M. \& WADSTROM, T. (1982). Binding of fibronectin to the surface of group $A, C, G$, streptococci isolated from human infections. European Journal of Clinical Microbiology 1, 381-387.

Trent, J. M., Davis, J. R. \& Payne, C. M. (1980). The establishment and morphological characterisation of finite cell lines from human endometrium. American Journal of Obstetrics and Gynecology 136, 352-362.

Ward, M. E. \& Murray, A. (1984). Control mechanisms governing the infectivity of Chlamydia trachomatis for HeLa cells: mechanisms of endocytosis. Journal of General Microbiology 130, 1765-1780. 